\title{
Simultaneous optical and radar signatures of poleward-moving auroral forms
}

\author{
A. Thorolfsson ${ }^{1}$, J.-C. Cerisier ${ }^{1,2}$, M. Lockwood ${ }^{3,4}$, P. E. Sandholt ${ }^{5}$, C. Senior ${ }^{1}$, M. Lester $^{6}$ \\ ${ }^{1}$ Centre d'étude des Environnements Terrestre et Planétaires, 4 avenue de Neptune, 94107 Saint-Maur CEDEX, France \\ ${ }^{2}$ Université Pierre et Marie Curie, 4 place Jussieu, 75005 Paris, France \\ ${ }^{3}$ Department of Physics and Astronomy, University of Southampton, Highfield, Southampton, SO17 1BJ, United Kingdom \\ ${ }^{4}$ Space Science Department, Rutherford Appleton Laboratory, Chilton, Didcot, OX11 0QX, United Kingdom \\ ${ }^{5}$ Department of Physics, University of Oslo, P.O. Box 1048, Blindern, N-0316, Norway \\ ${ }^{6}$ Department of Physics and Astronomy, University of Leicester, Leicester LE1 7RH, United Kingdom
}

Received: 8 December 1999 / Revised: 16 May 2000 / Accepted: 26 May 2000

\begin{abstract}
Dayside poleward moving auroral forms (PMAFs) were detected between 06:30 and 07:00 UT on December 16, 1998, by the meridian scanning photometer and the all-sky camera at Ny Alesund, Svalbard. Simultaneous SuperDARN HF radar measurements permitted the study of the associated ionospheric velocity pattern. A good general agreement is observed between the location and movement of velocity enhancements (flow channels) and the PMAFs. Clear signatures of equatorward flow were detected in the vicinity of PMAFs. This flow is believed to be the signature of a return flow outside the reconnected flux tube, as predicted by the Southwood model. The simulated signatures of this model reproduce globally the measured signatures, and differences with the experimental data can be explained by the simplifications of the model. Proposed schemes of the flow modification due to the presence of several flow channels and the modification of cusp and region 1 field-aligned currents at the time of sporadic reconnection events are shown to fit well with the observations.
\end{abstract}

Key words: Ionosphere (auroral ionosphere; plasma convection) - Magnetospheric physics (magnetopause; cusp and boundary layers)

\section{Introduction}

During periods when the north-south component of the interplanetary magnetic field (IMF) is negative, a common signature observed by meridian scanning photometers around noon are the poleward moving auroral forms (PMAFs) (e.g. Sandholt et al., 1990).

Correspondence to: A. Thorolfsson

e-mail: thorolfs@cetp.ipsl.fr
These structures have been identified as the ionospheric signature of sporadic reconnection at the magnetopause, between interplanetary and magnetospheric flux tubes.

Once reconnected, the flux tubes are dragged through the ambient plasma under the magnetic tension force due to the strong field line curvature. Southwood (1987) has proposed a qualitative model of the ionospheric plasma flow in and around a reconnected flux tube. In the model, field-aligned currents (FACs) flow down one side of the flux tube and up the other. The current closure is achieved by horizontal Pedersen currents in the ionosphere. The corresponding plasma flow exhibits a twin-vortex pattern, the ambient plasma being driven from the front to the back of the tube. Using this model, several authors (McHenry and Clauer, 1987; Wei and Lee, 1990; Lockwood, 1991; Chaston et al., 1993) have quantitatively modelled the convection vortices associated with the motion of the flux tube, and the ground magnetometer signature of the associated current system. These signatures are highly variable, depending on the position of the magnetometer and the characteristics of the convecting flux tube. Chaston et al. (1993) concluded that a reconnection signature cannot be identified on the basis of single magnetometer observations and that a station array is at least necessary. Farrugia et al. (1989) showed that travelling convection vortices induced by solar wind pressure pulses, could mimic the magnetometer signatures predicted for an isolated circular convecting flux tube.

When observed with an HF radar, reconnected flux tubes appear generally as regions of temporally enhanced flow velocity called "flow channels" (e.g. Pinnock et al., 1995; Rodger and Pinnock, 1997; Provan et al., 1998; Milan et al., 1999). The flow channel moves longitudinally under the influence of the $B_{y}$ component of the interplanetary magnetic field (IMF) and then drifts poleward. Its phase velocity (deduced from the drift of the event as a whole) is equal to, or of the same order as, the flow velocity, as predicted by the Southwood (1987) model. In a case study, Milan et al. (1999) have also shown the co-location of flow channels and 
PMAFs. In the studies mentioned the predicted return flow of the ambient plasma in the vortices has been elusive, although Pinnock et al. (1993) reported on data that indicate the presence of return flow. Lockwood et al. (1990) inferred from magnetometer data that weak return flow existed on either side of a flow channel observed using the EISCAT radars. Recently, Sandholt et al. (1999) also used magnetometers to show the existence of return flow on the equatorward side of a PMAF, observed with Svalbard optical instruments. As this return flow is an essential part of the Southwood (1987) flow model, the study of its presence and characteristics are important for the understanding of FTE flow patterns and reconnection models. Lockwood et al. (1990) and Lockwood (1991) noted that the ratio of the peak return flows to the event phase velocity was set by the ratio of the event dimension along and perpendicular to the direction of event motion. The low values of this ratio (i.e. weak return flows) for events moving longitudinally were in agreement with the extended longitudinal dimension of the flow channels.

We report on a case study of simultaneous observations of PMAFs and flow channels on December 16, 1998, between 06:30 and 07:00 UT. Two papers have already been devoted to the study of the same time period. McCrea et al. (1999) have described the largescale flow for the 06:00-09:00 UT period. Lockwood et al. (submitted 1999) studied the small-scale thermodynamic structure in the ionosphere between 06:30 and 07:05 UT, using mainly the ESR radar in Svalbard and the Ny Alesund meridian scanning photometer. The present work is aimed at studying the detailed small scale convection in and around the flow channels. We compare these observations with a simulation of the Southwood (1987) model of incompressible flow around a reconnected flux tube, which we superimpose on largescale convection arising from another source of flow.

\section{Observations}

\subsection{Instrumentation}

The CUTLASS HF radar at Hankasalmi, Finland $\left(62.3^{\circ} \mathrm{N}, 26.6^{\circ} \mathrm{E}\right)$ is a part of the extended network of HF radars called SuperDARN (Super Dual Auroral Radar Network) (see Greenwald et al., 1995, for further description). The radars measure line-of-sight (l-o-s) plasma flow velocities in the $\mathrm{E}$ and F-regions of the ionosphere. The field-of-view of the Finland radar is roughly centred over Svalbard (see Fig. 1). On December 16, 1998, the Finland radar was operated in a special mode allowing a high time resolution on three of the sixteen possible beam directions (beams $5,7,9$ ), together with a nearly complete l-o-s velocity map (beams 1 to 14) every three minutes. Beam 7 , which has the highest time resolution (10 s), is directed towards magnetic north. While completing the full map (which takes one minute), the high resolution is maintained on beam 7 . The SuperDARN radar data are presented in both geographic and AACGM geomagnetic coordinates

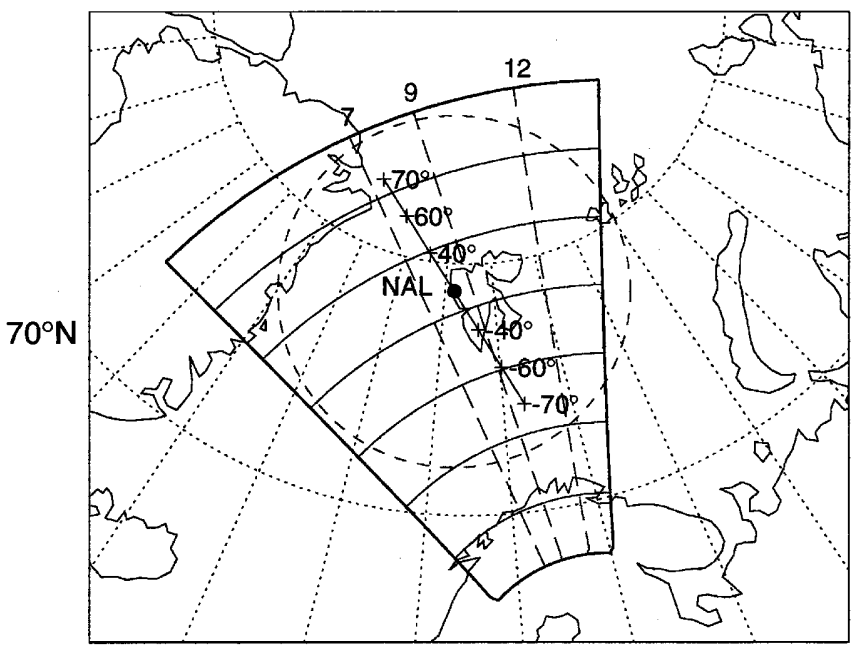

Fig. 1. The instrumental arrangement around Svalbard. The field-ofview of the Finland SuperDARN radar is delimited by the thick solid lines. High-resolution beams 7 and 9, as well as the low-resolution beam 12, are shown with long dashes. The solid line centred on $\mathrm{Ny}$ Alesund $(N A L)$ indicates the beam of the meridian scanning photometer. Several zenith angles are shown in the figure. The extreme limit of the Ny Ålesund all-sky camera is shown by the dashed circle

(altitude-adjusted CGM coordinates) (see Baker and Wing, 1989).

Optical observations have been obtained from two instruments at Ny Ålesund, Svalbard, situated at $78.9^{\circ} \mathrm{N}$ and $11.9^{\circ} \mathrm{E}$ in geographical coordinates $\left(76^{\circ}\right.$ magnetic latitude). The meridian scanning photometer (MSP) is oriented approximately along the magnetic meridian and follows closely beam 9 of the Finland radar. The MSP has an $18 \mathrm{~s}$ resolution on four wavelengths, but only the red line $(630 \mathrm{~nm})$ emission will be used here. The Ny Allesund all-sky camera (ASC) has a $2 \mathrm{~s}$ integration time, and provided images every minute of the $630 \mathrm{~nm}$ emission in the period studied.

Data from the Wind satellite is used to obtain information on the interplanetary magnetic field and the dynamic pressure. During the period under study, the spacecraft was on the morning side of the magnetosphere, approximately at $(X, Y, Z)=(4,-26,24) R_{E}$ in GSM coordinates.

\subsection{Solar wind conditions}

Figure 2 shows the IMF and the solar wind dynamical pressure measured by Wind during the 06:00 to 08:00 UT period. The period under discussion is the fairly steady period between 06:22 and 07:30 UT, but special attention is given to the 06:30-07:00 UT period, indicated by vertical lines in the figure. This time interval is characterized by negative $B_{z}$ and $B_{y}$, after a period of positive $B_{z}$. The solar wind pressure was rather steady between 2 and $3 \mathrm{nPa}$, with a mean value at around $2.3 \mathrm{nPa}$. The delay between the Wind spacecraft and the ionosphere is only a few minutes, the precise value being of no consequence for the analysis discussed here. 


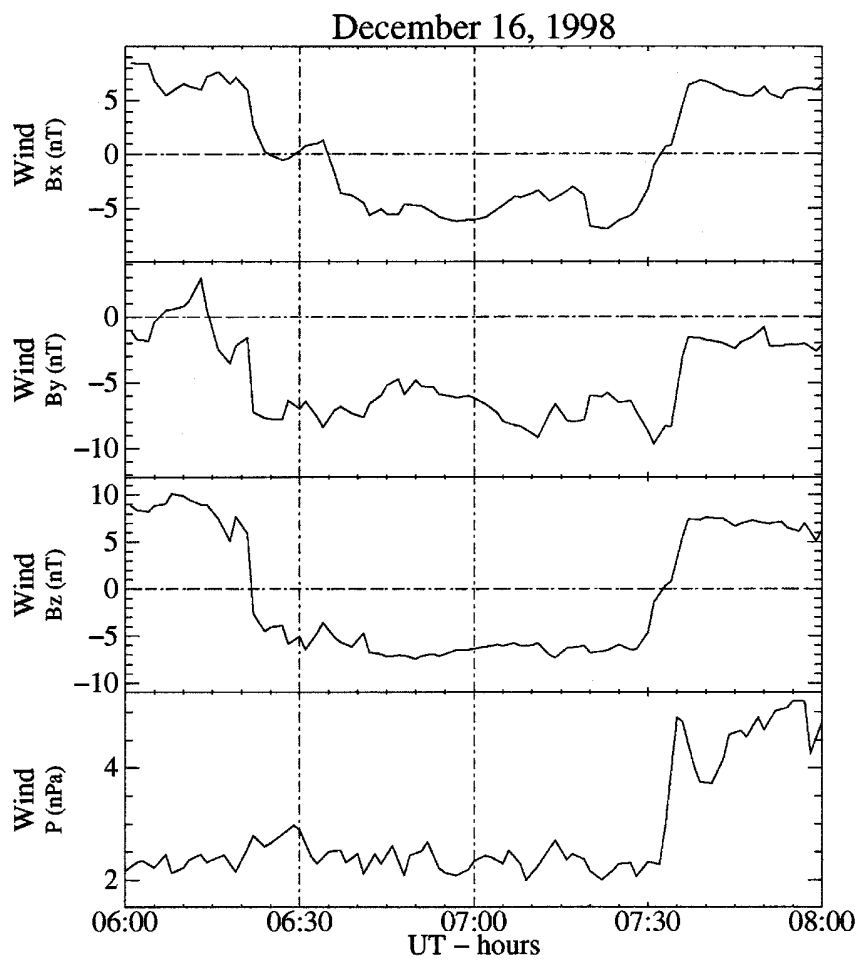

Fig. 2. IMF components $B_{x}, B_{y}$ and $B_{z}$ (in GSM coordinates) and the dynamic pressure of the solar wind. The period under study is delimited by the two vertical lines

\subsection{Optical data}

2.3.1 Meridian scanning photometer Figure 3 shows the MSP red line $(630 \mathrm{~nm})$ auroral emissions between 06:30 and 07:00 UT. Zenith angles southward of the station are in the lower half of the figure, and are shown with negative values in Fig. 1. During this period, the largescale auroral structure shows an equatorward motion of the auroral oval, which is consistent with the southward turning of the IMF (e.g. Sibeck, 1994, and references therein). McCrea et al. (submitted 1999) deduced also this motion from EISCAT and ground magnetometer data. Another large-scale variation is the progressive intensification of the mean auroral intensity observed as the oval drifts equatorward. A clear feature in the data are the strong brightenings that move poleward for a few minutes before disappearing (indicated by white arrows in the figure). These indicate the presence of poleward-moving auroral forms (PMAFs) of the type described by several authors and usually observed around noon under similar IMF conditions (e.g. Sandholt et al., 1990; Denig et al., 1993, Moen et al., 1995). The strong brightenings after 06:45 UT are clearly associated with an equatorward shift of the auroral equatorward boundary, a feature previously reported for PMAFs and associated with pulsed dayside reconnection (e.g. Sandholt et al., 1998b, and references therein). In the 06:40 to 07:00 UT period, six poleward moving brightenings can be detected, referred to by the letters a to $\mathrm{f}$ in the figure. This gives a mean repetition period of about $4.0 \mathrm{~min}$, which is of the same order as for previously reported PMAFs (e.g. Sandholt et al., 1990, 1998b).

A closer inspection of the poleward-moving intensifications shows that many of them appear to be made of several sub-structures, indicated by arrows and referred to by indices. This is particularly clear for events $\mathrm{d}$ and $\mathrm{e}$.

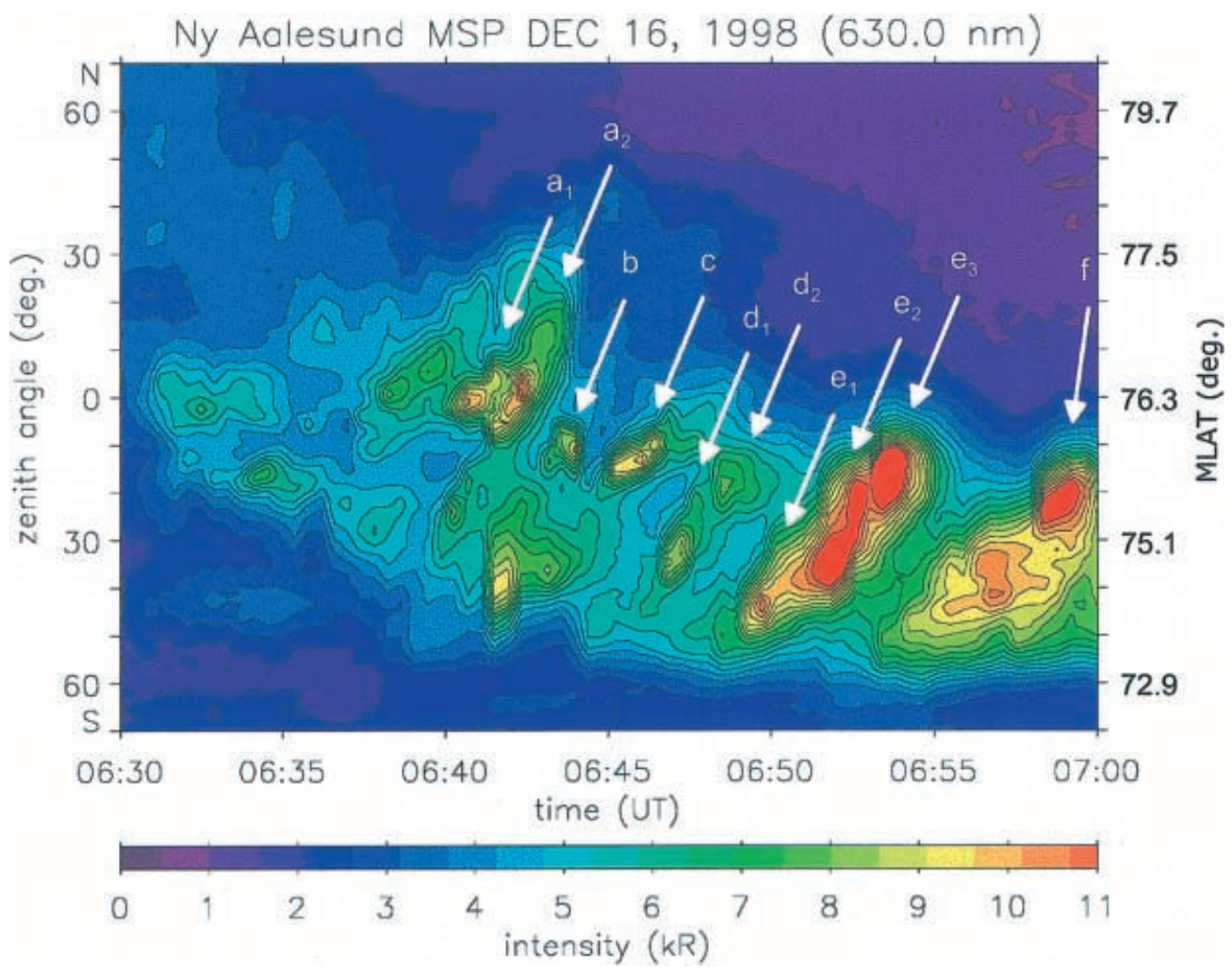

Fig. 3. Ny Ålesund Meridian Scanning Photometer measurements for the $630 \mathrm{~nm}$ wavelength. Zenith angles in the bottom half of the figure are southward of the station. The white arrows indicate poleward moving auroral forms (labelled $a$ to $f$ ) and their substructures (labelled with indexes). Magnetic latitudes (assuming an emission altitude of $250 \mathrm{~km}$ ) are shown to the right 
The mean sub-structure repetition time in these intervals is $80-120 \mathrm{~s}$. This rebrightening has previously been reported for PMAFs (e.g. Fasel et al., 1992-1994). According to their study, the delay between successive brightenings is typically $1.5-4 \mathrm{~min}$, which agrees well with the data presented here. Fasel et al. (1993) propose that the rebrightening is due to patchy multiple $\mathrm{X}$-line reconnection (Lee et al., 1993). Lysak et al. (1995) note that the delay is similar to the Alfvén wave transit time between the magnetopause and the ionosphere, and suggest that the successive brightenings might be due to an Alfvén bounce effect. Recently, Lockwood et al. (1999) proposed a new scheme for this rebrightening. They suggest that, after the initial brightening, the increased rate of recombination, due to combined effects of high ion flow velocities and Joule heating in a PMAF, leads to a decrease in auroral emissions. As the velocity of the flow channel decreases, the cusp/cleft precipitation reestablishes the plasma density, and auroral activity increases again.

2.3.2 All-sky camera Figure 4 shows two sequences of all-sky camera images obtained during the periods when clear signatures were recorded with the MSP (06:46 to
06:48 UT and 06:50 to 06:53 UT). For easier comparison, the approximate directions of the MSP and radar beams 7 and 9 are shown at 06:48 UT. Both camera sequences show east-west (in magnetic coordinates) aligned auroral structures which formed between $0^{\circ}$ and $10^{\circ} \mathrm{E}$ (shown with arrows) and then moved eastward and northward before disappearing after a few minutes. In the earlier sequence, there are also two large auroral structures in the eastern part of the f-o-v (between $20^{\circ} \mathrm{E}$ and $40^{\circ} \mathrm{E}$ ) that move poleward and disappear. In the second sequence, the sharply defined auroral form between $0^{\circ}$ and $10^{\circ} \mathrm{E}$ blends in with highly structured aurora that moves mainly poleward. At the time of the ASC scans, the region between $0^{\circ}$ and $10^{\circ} \mathrm{E}$ corresponds approximately to 8 MLT. The occurrence of PMAFs at such early hours might be somewhat surprising, but it is however in agreement with previous observations for similar IMF conditions (e.g. Sandholt et al., 1998a, and references therein).

A comparison between ASC and MSP optical data shows that the isolated eastward-moving structure observed in the ASC field of view between 06:46 and 06:48 UT is clearly detected as a poleward-moving form in the MSP data. The latter sharply defined structure

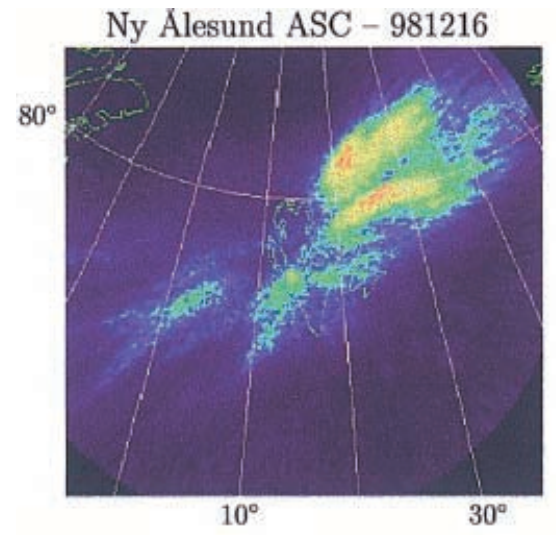

(a) 06:46 UT

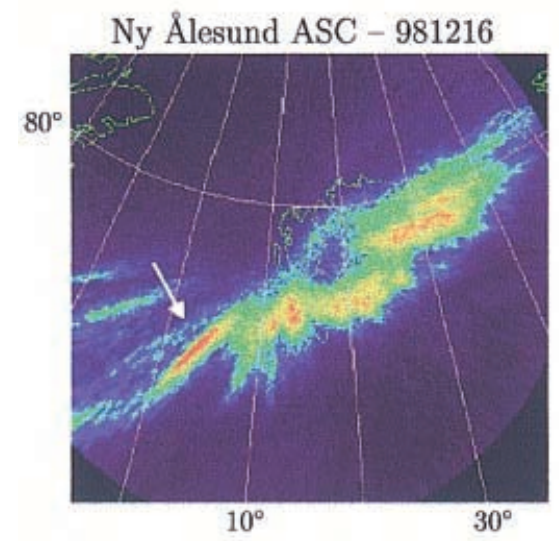

(d) 06:51 UT

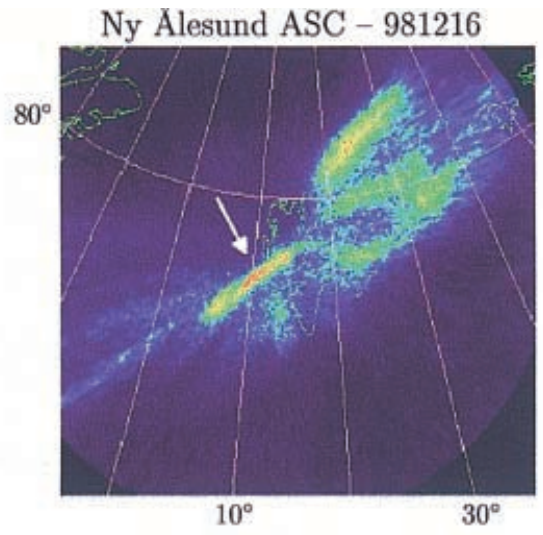

(b) 06:47 UT

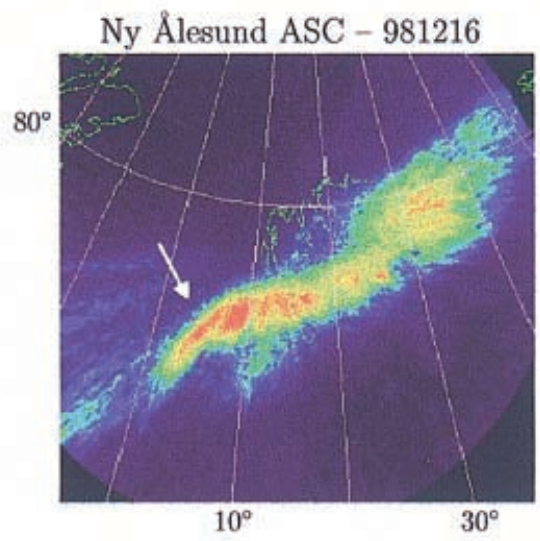

(e) $06: 52$ UT

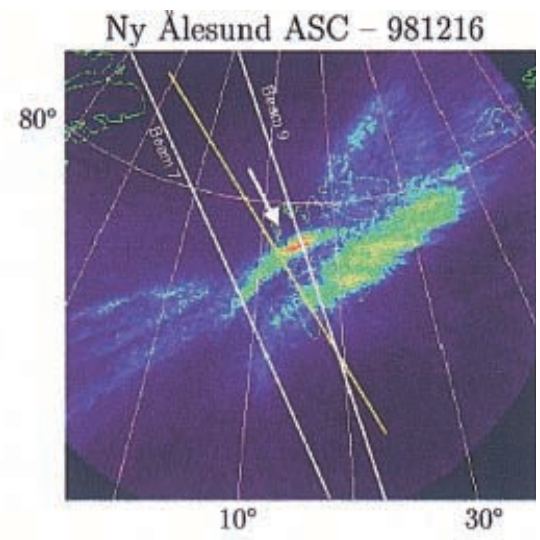

(c) 06:48 UT

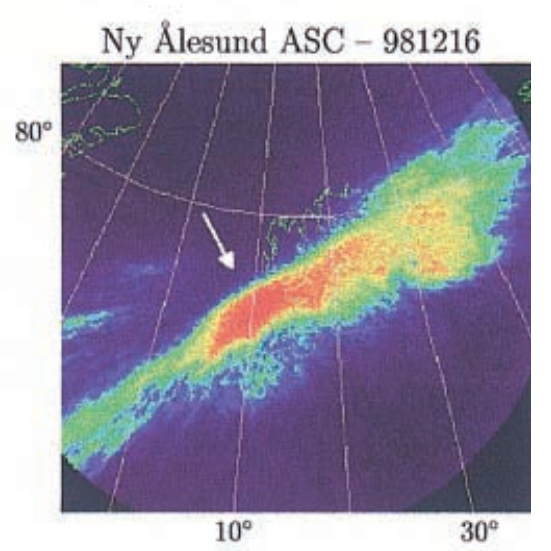

(f) $06: 53$ UT
Fig. 4. Red light all-sky camera images from Ny Ålesund between 06:46 to $06: 48$ UT and $06: 51$ to $06: 53$ UT. The $630 \mathrm{~nm}$ aurora is projected to $250 \mathrm{~km}$. Auroral forms are seen to form at the western edge of the background aurora and move eastward and poleward (shown with arrows). The approximate directions of the MSP and radar beams 7 and 9 are shown at 06:48 UT 
(see Fig. 4d) is also detected with the MSP, but as a part of a larger auroral event. The observed eastward direction of motion is expected for PMAFs events in the morning sector for the prevailing IMF conditions $\left(B_{y}<0\right)$, as previously mentioned. These structures have thus all the characteristics of PMAFs and can be attributed to magnetic reconnection.

The individual auroral structures observed with the ASC in Fig. 4 show somewhat different eastward (magnetic) movement. For example, Fig. 4b, c shows that the thin auroral form centred on $10^{\circ} \mathrm{E}$ drifts essentially eastward while the two larger structures between about $20^{\circ} \mathrm{E}$ and $40^{\circ} \mathrm{E}$ drift mainly poleward. This observation can be explained by magnetic tension considerations (Heelis, 1984). For the present IMF configuration, a flux tube reconnected at the magnetopause far from noon has greater curvature than one reconnected closer to noon, and thus a higher magnetic tension (e.g. the schematic in Fig. 7 in Lockwood et al., 1999). For two separate flux tubes, the one reconnected farther from noon on the morning side drives a higher eastward flow, which translates also into a greater eastward drift.

\subsection{HF radar data}

2.4.1 General convection characteristics The first panel in Fig. 5 shows the Finland radar 1-o-s velocity map measured at 06:30 UT. The data is presented in geographical coordinates for easier comparison with ASC data, but magnetic latitude contours are also shown (solid lines). The 06:30 UT time period is chosen to describe the large-scale plasma flow for negative IMF $B_{z}$ when no PMAFs are observed. Negative velocities are observed in the easternmost beams, while positive velocities are observed on the western beams. This is consistent with an eastward large-scale flow, as can be expected for the prevailing IMF conditions (negative $B_{y}$ ) in the morning side of the ionosphere (see also the analysis by McCrea et al., (submitted, 1999)). On average, the transition between positive and negative velocities between 06:30 and 07:00 UT is observed on beam 6 , which is directed $3^{\circ}$ west of magnetic north. This indicates that the large-scale plasma flow is almost purely longitudinal. This flow is also consistent with the magnetometer data described by McCrea et al. (1999).

Figure 5 also shows a sequence of maps between 06:42 and 07:00 UT, in a period when many PMAFs were observed with the MSP (See Fig. 3). The comparison with the map at 06:30 UT shows that there is considerably more structure in the flow when PMAFs are present. The high-speed negative flow (orange and red coded velocities) are similar to the flow channel structures previously observed (e.g. Pinnock et al., 1995; Provan et al., 1998; Milan et al., 1999). The positive (equatorward and/or westward) flow detected in the easternmost beams indicates vorticity in the convection and is reminiscent of the return flow outside a reconnected flux tube, as modelled by Southwood (1987). These poleward and equatorward flow structures are studied in greater detail later.
Figure 6 shows the line of sight (1-o-s) velocity measured on two of the high-resolution beams (beams 7 and 9), and beam 12, as a function of magnetic latitude (MLAT) and universal time. Geographic latitude (GLAT) is shown on the right vertical axis. Beam 9 displays enhanced negative (poleward) flow velocities (flow channels), most of them moving poleward along the radar beam. Assuming an emission altitude of $250 \mathrm{~km}$ for the red line, the position of several MSP observations have been reported on the middle panel (beam 9) in Fig. 6. The solid lines represent estimated fits (fits-by-eye) to red line emission intensities. This comparison shows that each flow channel in radar data is associated with a PMAF observed with the MSP, which confirms recent similar observations by Milan et al. (1999). These authors have shown a good colocalisation of flow channels and PMAFs, but we cannot deduce from the present data whether these two signatures are perfectly co-localised or not. This problem arises mainly from incertainties in the geographical mapping of both the auroral and radar data, which in turn are related to the incertainty in the emission altitude of the red line emission and the altitude of the radar backscatter. Another factor is the event propagation time from the MSP meridian to beam 9. However, as two selected flow channel events are discussed in detail later, we show that their size and behaviour is similar to that of the associated PMAFs.

Superimposed on the velocity diagram, the dashed line in the middle panel of Fig. 6 (beam 9) shows the lowlatitude limit of large spectral width (larger than $150 \mathrm{~m} / \mathrm{s}$ ) in radar data. This limit between narrow and wide HF spectra has been shown to indicate the position of the separatrix between closed and opened field lines in the cusp (Baker et al., 1997; Pinnock et al., 1999). This limit correlates closely with the low-latitude boundary of the red line emissions at the level of $3 \mathrm{kR}$ (shown by the dotted line), after the initial period of equatorward drift of the auroral emission. A similar correlation has been observed by Milan et al. (1999) between the $1.5 \mathrm{kR}$ lowlatitude limit and the $10 \mathrm{~dB}$ backscatter power. These results indicate a strong relationship between optical intensity and properties of HF radar data. The data in beam 9 show also that the velocity flow channels are initiated close to the equatorward edge of $630 \mathrm{~nm}$ dominant aurora before propagating poleward.

2.4.2 06:47 UT event The ASC sequence from 06:46 to 06:48 UT (See Fig. 4) shows the development of a thin arc at around $10^{\circ} \mathrm{E}$, elongated in the magnetic east-west direction. The arc moves mainly eastward with a phase velocity of the order of $1.9 \mathrm{~km} / \mathrm{s}$. Between 06:47 and 06:48 UT, the shape of the arc changes from linear to being curved, indicating a northward motion of the central part of the arc.

The associated flow channel is observed on beam 9 of the HF radar between 06:46 and 06:47:30 UT. The precise time of the start of the flow channel cannot be stated, because of the lower resolution due to the scanning over the full set of radar beams between 06:45 and 06:46 UT. The flow channel is mainly absent in 

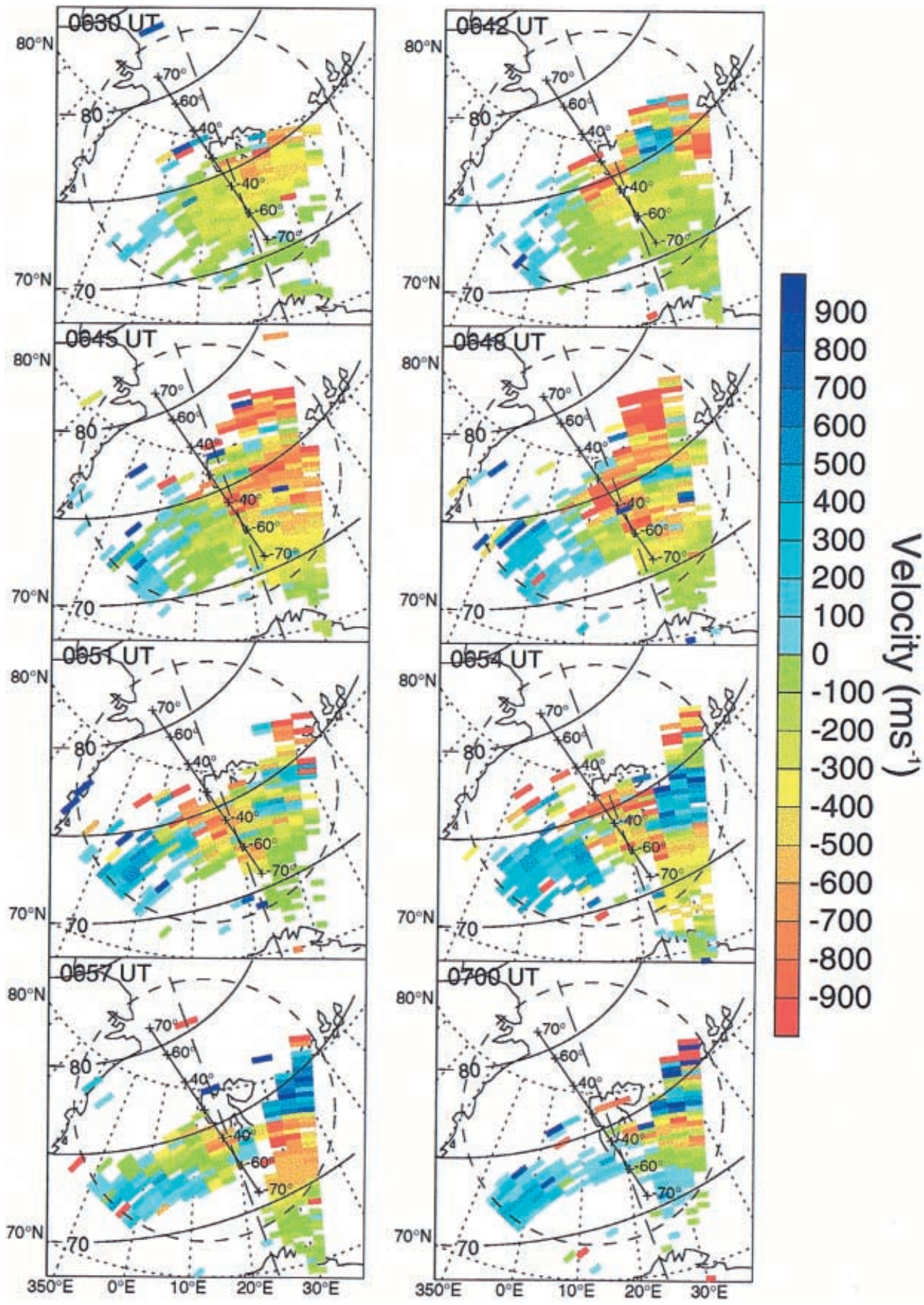

Fig. 5. Radar data on December 16,1998 , in geographical coordinates. The 1-o-s velocity is colour coded, negative velocity indicating flow away from the radar and positive velocity indicating flow towards the radar. Several magnetic isolatitudes are shown with solid lines. The MSP and beam 9 line-of-sights are shown with solid and dashed lines, respectively

beam 7 , although some signatures are detected at $74^{\circ}-$ $75^{\circ}$ MLAT between 06:47 and 06:48 UT. This is consistent with the limited longitudinal range of northward motion deduced from the ASC data (observed mainly eastward of beam 7 in Fig. 4), but may also be because the flow is closer to being perpendicular to beam 7 than to beam 9. During the event, the radial velocity measured on beam 9 is about $1.2-1.3 \mathrm{~km} / \mathrm{s}$. If one assumes that the $1.9 \mathrm{~km} / \mathrm{s}$ phase velocity, deduced from the ASC data, represents also the velocity in the associated flow channel, then the northward (magnetic) velocity component is about $1.0 \mathrm{~km} / \mathrm{s}$.
The MSP optical data associated with this event are the red line emissions between 06:46:30 and 06:48 UT (event $\mathrm{d}_{1}$ in Fig. 3). The comparison of optical and radar data in the middle panel of Fig. 6 show that there is a slight delay (about $1 \mathrm{~min}$ ) from the flow channel observed by the radar and the MSP observations.

Judging from the ASC image at 06:47 UT, the dimensions of this isolated structure are about $40 \mathrm{~km}$ in latitude and $400 \mathrm{~km}$ in longitude, which agrees well with previous ASC observations (e.g. Sandholt et al., 1990). This corresponds also well to the dimensions of the flow channel observed in the velocity map at 


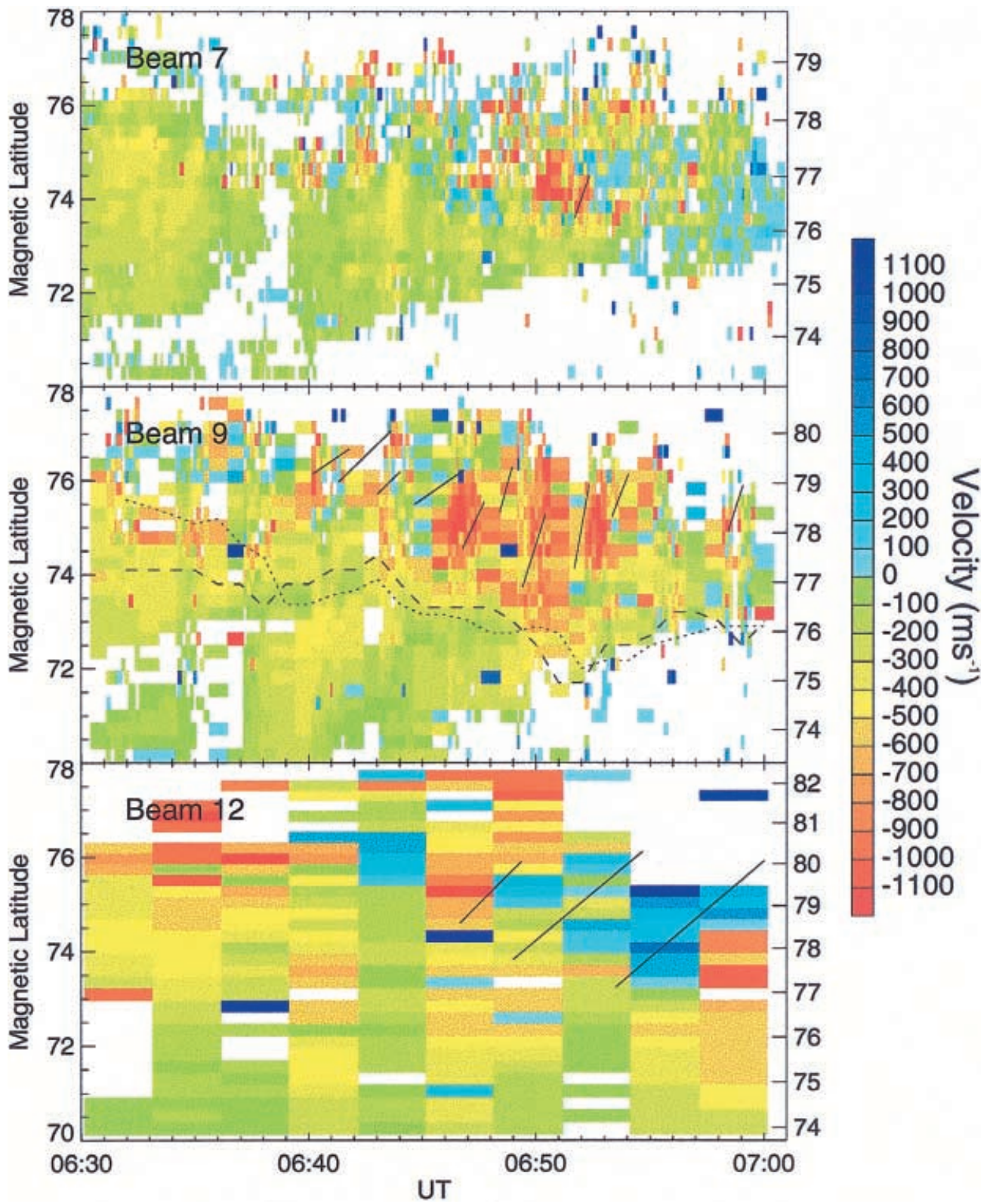

Fig. 6. Line-of-sight velocity from the Finland SuperDARN radar for beams 7, 9 and 12. The data is shown in magnetic latitude as a function of time. The right vertical axis shows the geographic latitude. The short solid line superimposed on beam 7 data shows a small flow channel. For beam 9, the dashed line represents the $150 \mathrm{~m} / \mathrm{s}$ spectral width boundary in the radar data. The dotted line at similar latitudes shows the $3 \mathrm{kR}$ boundary in $630 \mathrm{~nm}$ MSP data. The short solid lines are fits-by-eye to selected $630 \mathrm{~nm}$ intensifications. The $630 \mathrm{~nm}$ emissions have been mapped assuming an emission altitude of $250 \mathrm{~km}$. The solid lines in beam 12 data show fitsby-eye to the global structure of three PMAFs in MSP data
06:48 UT (see Fig. 5) in beams $7-10$ at around $75^{\circ}$ MLAT.

2.4.3 06:52 UT event The 1-o-s velocities in beam 7 (top panel in Fig. 6) show a small flow channel observed between 06:51:30 and 06:52:30 UT, indicated by a solid line. The same event is observed about $80 \mathrm{~s}$ later on beam 9, at a higher latitude (both magnetic and geographic). At these latitudes, beams 7 and 9 are about $100 \mathrm{~km} / \mathrm{s}$ wide, and the distance between the centre of beams 7 and 9 is thus about $200 \mathrm{~km}$. The delay between the event detection on these two beams indicates an eastward (magnetic) phase velocity of about $2.4 \mathrm{~km} / \mathrm{s}$. However, the flow localisation within a radar cell of measure is not precise, so this value can only be used as an indicator of the eastward phase velocity. The flow velocities of this event can be deduced from the 1-o-s velocities measured on beams 7 and 9. They yield a northward (magnetic) component of $1.0 \mathrm{~km} / \mathrm{s}$ and an eastward component of $1.8 \mathrm{~km} / \mathrm{s}$, similar to that obtained in Sect. 2.4.2. The eastward flow velocity is comparable to the $2.4 \mathrm{~km} / \mathrm{s}$ eastward phase velocity, which supports the Southwood (1987) flow model.

The MSP optical data associated with this event are the intense red line emissions between 06:51 and 06:53 UT (event $e_{2}$ in Fig. 3). This intensification is a substructure of a long-lasting auroral event starting at 06:49 UT. The ASC sequence of images between 06:51 and 06:53 UT (see Fig. 4) show the poleward and eastward motion of a thick arc, in agreement with this picture. The small delay (less than $1 \mathrm{~min}$ ) between the MSP event and the flow channel is consistent with the eastward motion of the structure from the MSP meridian to beam 9 (see Fig. 1 and 4). Other events show a lag that is similar (event $\mathrm{e}_{3}$ ) or even less (events $\mathrm{e}_{1}$ and f). Only event $\mathrm{d}_{1}$ shows an inversed lag, as already mentioned. 
2.4.4 Return flow velocities The data discussion in the preceding sections showed the relatively good correspondence between PMAFs detected in the optical data (MSP and ASC) and flow channels in radar data (poleward and eastward velocities). The radar velocity maps in Fig. 5 show also the presence of patches of equatorward and/or westward velocities in the vicinity of the flow channels, which indicates the presence of the return flow, as modelled by Southwood (1987). This possibility is analysed later.

The bottom panel in Fig. 6 shows the radar data in beam 12, which is to the east of beam 9 (see Fig. 1). Although the temporal resolution is low (one scan every $3 \mathrm{~min}$ ), the patches of positive flow yield important information. The data between 06:39 and 07:00 UT show clearly that the positive flow patches shift equatorward with time, following the general movement of the equatorward red line boundary. The flow intensity increases also with time, exactly as the red line auroral intensity. After 07:00 UT, PMAFs move essentially eastward through the MSP meridian (see the discussion Lockwood et al., 1999, and their Fig. 1). From that same moment, the positive flow patches disappear from the data in beam 12 (not shown). These observations suggest a relation between the positive flow and the PMAFs.

To test this further, the global structure (not individual sub-structures) of three $630 \mathrm{~nm}$ PMAFs has been plotted on the beam 12 data (events $d$, e and $f$, shown with solid lines). The auroral and radar data comparison shows that there is excellent agreement between the latitude of the equatorward edges of the PMAFs and the positive l-o-s velocity patches. Both also show a similar equatorward shift with time.

When comparing the PMAF to the radar data, one has to bear in mind that beam 12 is about $300 \mathrm{~km}$ to the east of the MSP meridian and that the time resolution on beam 12 is poor, since the data is acquired once every $3 \mathrm{~min}$. It is thus to be expected that there be some delay between MSP and beam 12 data. If examined carefully, the beam 12 data show three poleward progressions of flow patches in the period between 06:48 and 07:00 UT. The poleward drift of these patches is much slower than that of the individual PMAF sub-structures plotted onto beam 9 data, but it compares well with that of the global PMAF structures. This strengthens further the idea of a relationship between the PMAFs and the positive velocity patches. These flow patches could thus be the signatures of the return flow outside reconnected flux tubes, in agreement with the Southwood (1987) model. To examine this hypothesis, we simulated this modelled flow in the field-of-view of the Finland SuperDARN radar.

\section{Simulated signatures of a reconnected flux tube}

\subsection{Quantification of the Southwood (1987) model}

Wei and Lee (1990) and Lockwood (1991) have proposed a quantitative ionospheric convection model for FTEs, inspired by the Southwood (1987) model. This convection model supposes a two-dimensional ionosphere with uniform conductivity. At the footprint of the reconnected flux tube in the ionosphere, they suppose an uniform elliptical plasma cloud that travels through the ambient plasma as the flux tube is pulled by magnetic tension. As in the Southwood (1987) model, the flow velocity inside the cloud is the same as the phase velocity of the cloud itself. The flow is divergence-free everywhere, curl-free except at the cloud border, and zero at infinity.

The results of Wei and Lee (1990) can be used to calculate the theoretical ionospheric flow resulting from an FTE as detected by SuperDARN radars. As the radars measure the 1-o-s velocity component, the calculated velocity vector has to be projected onto the l-o-s of each radar beam.

There are four free parameters in the Wei and Lee (1990) model: the cloud extension in latitude and longitude, the phase velocity of the cloud and the direction of motion (flow angle) with respect to magnetic north. We used both ASC and radar data to obtain the dimensions of individual PMAFs and the associated flow channels, and to estimate the velocity. Typical dimensions are $40-120 \mathrm{~km}$ in latitude and $400-700 \mathrm{~km}$ in longitude, which agrees with previous results (e.g. Sandholt et al., 1990). The phase velocity is between 0.8 and $2.0 \mathrm{~km} / \mathrm{s}$, and flow angles between $30^{\circ}$ and $70^{\circ}$ east of magnetic north.

3.1.1 Application to radar data Figure 7 shows two examples of simulated flow structures, superimposed on a purely eastward (magnetic) background flow of $600 \mathrm{~m} / \mathrm{s}$. This background flow is, in general, different from the flow within the event. This means that the background flow is not driven by reconnection in the same location and by the same IMF and solar wind as for the event. If it were due to reconnection in the same place, then the IMF and/or solar wind must have changed so that the flow produced is different. All field lines reconnected in the same place to the same IMF/ solar wind would experience the same forces and undergo the same pattern of motion. The interplanetary observations on this day show no significant changes (see Fig. 2) and so we can eliminate that possibility. The background flow could be driven by ongoing reconnection elsewhere on the magnetopause, for which the combination of the tension force and sheath flow is different (Lockwood et al., 1999). Alternatively, the flow could be associated with ongoing reconnection in the tail current sheet (see Fox et al., 1994).

The simulations are not intended to reproduce exactly the radar signatures, but rather to be a basis for a comparison between the Southwood (1987) model and real data. Figure 7a shows the flow due to a single structure, with a longitudinal extent of $500 \mathrm{~km}$ and drifting with a velocity of $1.6 \mathrm{~km} / \mathrm{s}$ with respect to the background convection in a direction of $65^{\circ}$ to the east of magnetic north. This example was chosen to mimic the flow situation at 06:48 UT 


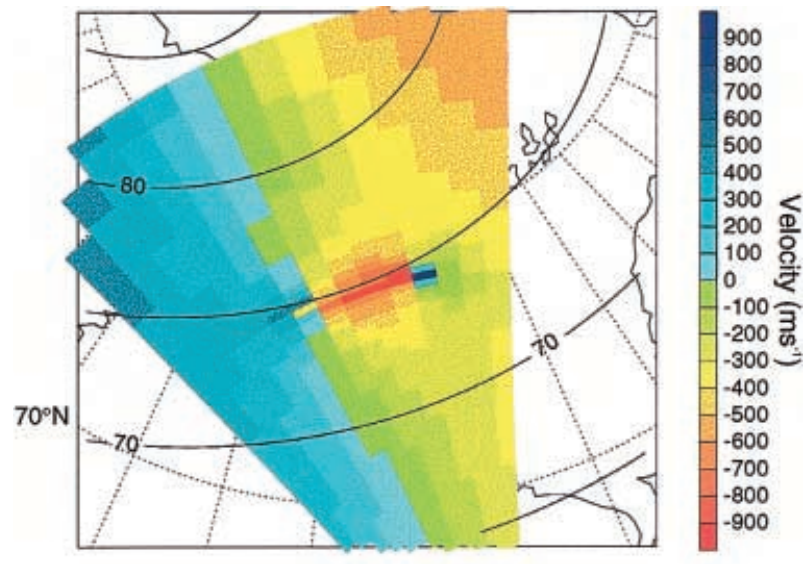

(a) One simulated flow channel

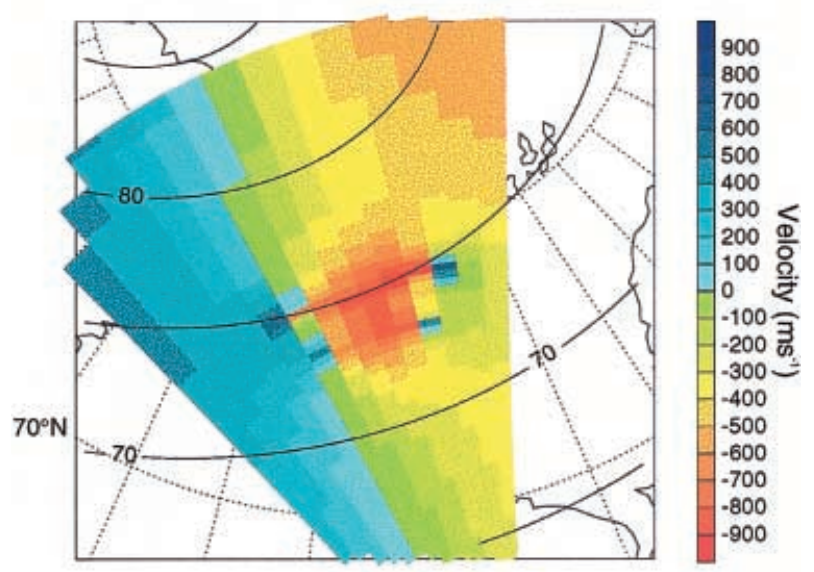

(b) Two simulated flow channels

Fig. 7a, b. Simulated HF radar data in geographical coordinates. Several magnetic isolatitudes are shown with solid lines. a single flow channel; b two flow channels

in Fig. 5. As expected, the eastward and poleward flow in the structure is detected as negative flow in radar data. The return flow outside the structure is detected as positive velocities at the east- and westward edges.

Since both radar and ASC data show the presence of more than one structure in the $\mathrm{f}-\mathrm{o}-\mathrm{v}$, it is necessary to simulate the flow due to at least two structures. This kind of simulation can indicate how flow from one interacts with the flow from the other. Figure $7 \mathrm{~b}$ shows two structures at the same longitude. The structures have both flow angles of $40^{\circ}$, and the poleward and equatorward structures have velocities of 0.8 and $0.5 \mathrm{~km} / \mathrm{s}$ and longitudinal extents are $600 \mathrm{~km}$ and $450 \mathrm{~km}$, respectively. This type of situation can be observed at 06:42 and 06:54 UT.

We recall that the quoted velocities are given relative to the uniform $600 \mathrm{~m} / \mathrm{s}$ eastward background velocity. The latitudinal extent of all the simulated structures is $40 \mathrm{~km}$, but the apparent extent is larger due to the plasma cloud pushing and pulling the incompressible plasma surrounding the structure.

\section{Discussion}

\subsection{Simulated flow}

The simulated flow in Fig. 7a, based on the Southwood (1987) model for FTEs, reproduces the main features expected: the negative (poleward) flow in the center of the event and the positive (equatorward) return flow at the edges. A comparison with Fig. 5 shows that the simulated flow intensities inside and outside the structure are similar to those observed in real data. The model can thus be judged to be successful in predicting the plasma flow for an isolated FTE. However, there are some differences in the return flow between the real and simulated data that need some discussion.

The intensity of the simulated return flow at the eastern edge of the event is of the same order as the positive velocities in the real data, or only slightly higher. However, the spatial extent of the simulated return flow is much smaller than in Fig. 5, for example at 06:48 UT when a relatively isolated structure is observed at $75^{\circ}$ MLAT (see the discussion in Sect. 2.4.2). One explanation might be the deformation of the real events with time. The ASC images in Fig. 4 between 06:47 and 06:48 UT show this deformation, apparent in the leading (eastward) part of the PMAF. This deformation has also been reported by other authors (e.g. Sandholt et al., 1990 their Fig. 4b). The data in Fig. 5 at 06:48 UT indicates as well that the associated flow channel is curved. This deformation of the leading edge of the structure can result in a higher vorticity, and thus a greater equatorward return flow outside the flow channel itself.

Although the flow channel and the associated auroral structure at 06:48 UT are relatively isolated, the neighbouring structures might affect the flow. The example in Fig. 7b, inspired by the 06:54 UT velocity map in Fig. 5, shows how the presence of two structures can affect the overall flow. Since the ionosphere is considered to be incompressible, the flow pattern from one structure extends far beyond the spatial limits of the reconnected flux tube. However, it is clear from the comparison between the simulation and the 06:54 UT velocity map that the simulation cannot reproduce the positive velocity patch in the real data, neither in size nor in intensity. The spatial confinement of the simulated return flow is such that it does not add up efficiently. It is also clear that the possible cause evoked already for the smaller extent of the return flow in simulated data is not capable of explaining this difference, so other reasons must be sought.

Another difference between the real and simulated flow is the return flow on the westward edge of the moving structure. The simulated flow shows a clear return flow while it is not apparent in some maps in Fig. 5, for example at 06:42 and 06:45 UT. One of the limitations of the model used can perhaps explain this difference between real and simulated return flows, both at the east- and westward edges of the flow channels. In our calculations, the flow due to an FTE was simply superimposed on the background convection. It is 
however possible that the presence of FACs due to the FTE modifies the cusp and region 1 currents near the cusp. Figure 8 is reproduced from Lockwood et al., (1993a) (see their Fig. 1e, f), and shows the idealised ionospheric flow in the dayside Northern Hemisphere during $B_{z}<0$ and $B_{y}<0$ IMF conditions. Figure 8a shows the flow and associated cusp and region 1 FACs before a reconnection event, which has just taken place in Fig. 8b. The flow and the positions of the FACs in Fig. 8b are in agreement with the Southwood (1987) model. The region of red line auroral emissions associated with newly opened field lines is shown by the grey region in the figure. Within this region, the flow is mainly eastward, with a small northward component. The equatorward return flow is shown to be at the eastward edge of the structure. Both these features are detected in the radar data in the present study, and were also simulated successfully. However, there is no equatorward flow predicted on the west side of the structure, unlike in our simulation, but in agreement with the observations. The importance of the return flow on the east side of the structure stems from the fact that the eastward motion of the newly reconnected flux tubes affects mainly the flow on closed field lines (e.g. Fig. 4 by Cowley, 1998). It is thus not unlikely that in the simulation, the superposition of the FTE flow on the background convection is too simplistic, and that the global changes of the FACs in the cusp region have to be taken into account. That is however beyond the scope of this work.

The simulations are based on patches of newly opened flux that are fixed in shape. As pointed out earlier, this is not entirely consistent with the $630 \mathrm{~nm}$ emissions shown in Fig. 4. The evolution of the shape of the patches of newly opened flux produced by a reconnection burst was introduced by Cowley et al. (1991), and was an essential part of their theoretical prediction of "cusp ion steps" (Lockwood and Smith, 1992). Without this evolution, it is not possible for patches of newly opened flux to be appended directly to each other and so the contiguous, but stepped, precipitation of sheath ions that is observed would not be possible. In the next section, we illustrate how changes in the shape of the pattern can qualitatively explain some of the differences between the observed and simulated line-of-sight velocities (shown in Fig. 5 and 7, respectively).

\subsection{Flows due to a sequence of reconnection pulses}

Cowley et al. (1991) have studied the evolution of a patch of newly opened flux, and of the associated flow equipotentials, following an isolated pulse of reconnection. They presented this evolution for two cases, with small and large magnitude of the IMF $B_{y}$ component. Lockwood et al. (1993b) and Lockwood (1994) generalised the sequence for small IMF $B_{y}$ to allow for a sequence of reconnection pulses which are closer in time than the duration of the effects of each. The data presented here are for large IMF $\left|B_{y}\right|$ and the events have a mean repeat period of about 4 min. Cowley and Lockwood (1992) estimate that the effects of each reconnection pulse will last for $15-20 \mathrm{~min}$ after the pulse has ended. Thus the events discussed here are forming long before the flows due to the prior event have subsided and an explanation of the observed flows requires a generalisation of the kind given by Lockwood (1994), but for large IMF $\left|B_{y}\right|$. This is presented in Fig. 9, which are schematic illustrations for 4 instants, corresponding to radar maps in Fig. 5. In each panel, dusk is towards the right and dawn to the left and the vertical line is the meridian scanned by the MSP. Patches of newly open flux are shaded grey. The openclosed field line boundary (OCB), indicated by a thick line in the figure, is shifted locally equatorward where flux tubes have recently been reconnected. Dashed lines equatorward of the OCB show where newly opened flux is shortly to be produced by a reconnection pulse. Dashed lines poleward of the OCB delineate patches on which precipitation is fading as the field lines are appended to the lobe.

In order to generate these schematics, a number of rules have been followed. The flow within each patch of newly opened flux is consistent with the motion and distortion in shape of the event itself. Events move rapidly zonally and then progressively poleward as the curvature force decays and motion becomes slower and dominated by the magnetosheath sheath flow (Lockwood et al., 1989, 1990). Flow stream lines cross nonreconnecting ("adiaroic") segments of the open/closed boundary where that boundary is in motion (Siscoe and Huang, 1985). Regions influenced by more than one transient event give flow that is the superposition of the flow patterns due to each event individually. Flow stream lines close in loops because the ionosphere is

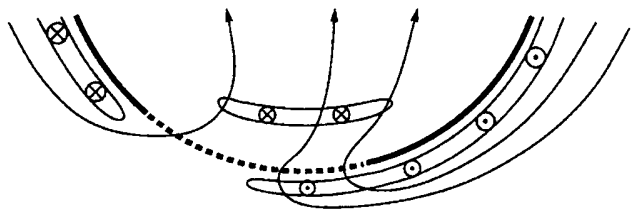

a)

12 MLT

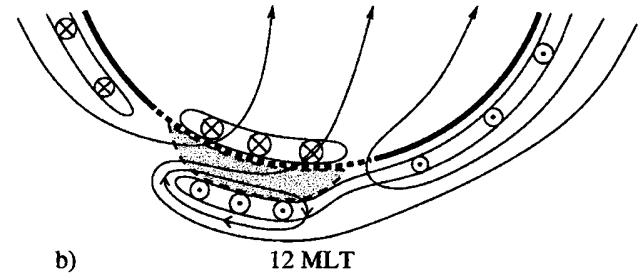

conditions before a reconnection event. b Shows the change in FACs and flow immediately after reconnection. The grey region in the figure indicates red line auroral emission
Fig. 8a, b. Figures reproduced from Lockwood et al. (1993a), showing the ionospheric flow, cusp and region 1 FACs in the dayside Northern Hemisphere during $B_{z}<0$ and $B_{y}<0$ IMF conditions. The thick dashed line indicates the merging line. a Shows the 

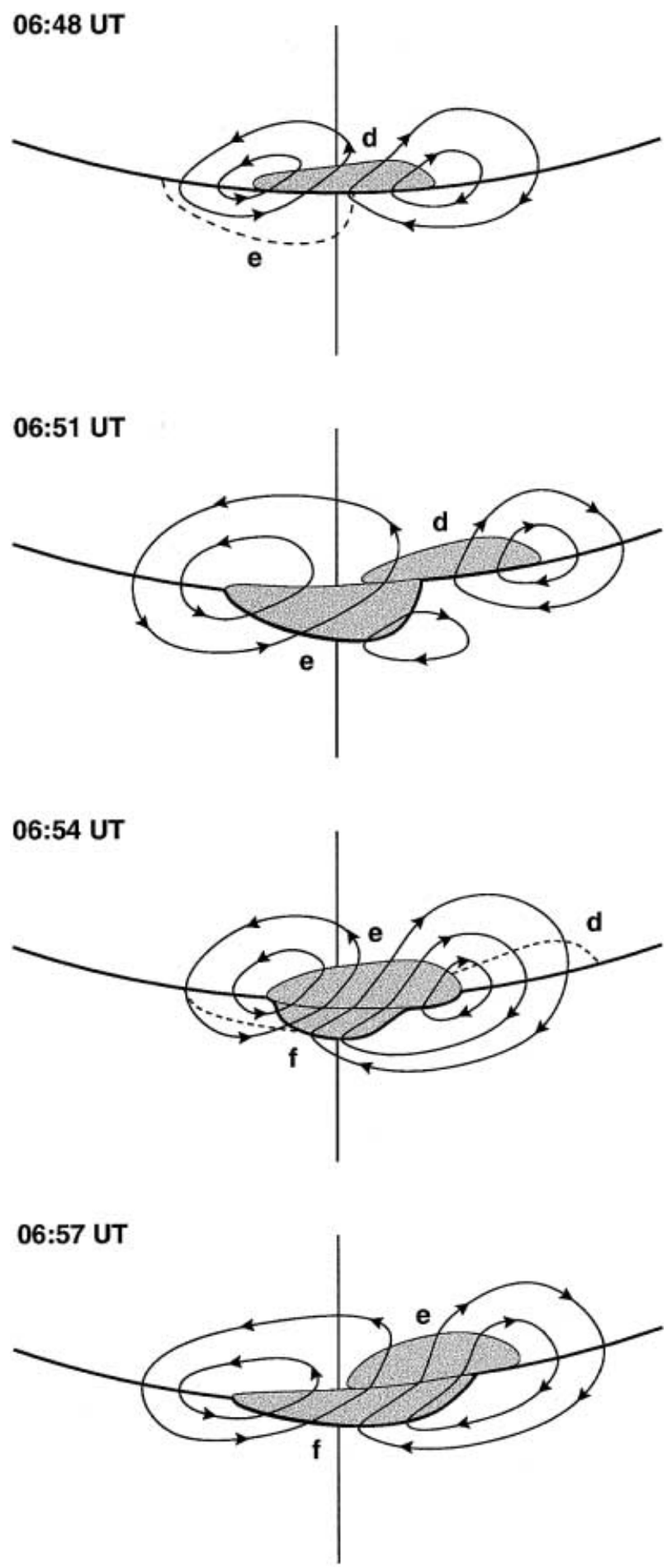

Fig. 9. Schematic of the evolution of patches of newly opened flux (shaded grey) and flow streamlines (lines with arrows) for certain times shown in Fig. 5. Dashed lines equatorward of the open-closed boundary (indicated with a thick line) show where the new events are about to form, those in the polar cap show old events on which significant precipitation has ceased. The vertical line in each plot is the meridian scanned by the MSP

incompressible. The events are labelled d-f according to the event identification from the MSP data (see Fig. 3). The same events have been labelled e-g by Lockwood et al. (1999). Along the MSP meridian, the patches of newly opened flux evolve poleward, as observed in Fig. 3 for the PMAFs. Event sizes, onset times and locations are chosen to fit the radar data shown in Fig. 5. Flow directions and speed must also match those derived from the radar data. The ASC data (see Fig. 4) has also been used to estimate the evolution of events. This data permitted us for example to deduce that event f was only partially developed at 06:54 UT, but fully developed at 06:57 UT. By following these rules, it is possible to arrive at the sequence of events shown in Fig. 9 that match the major features of the MSP, ASC and radar data.

A key difference between the "evolving patch" models of Cowley et al. (1991), Lockwood et al. (1993a, b) and Lockwood (1994) and the earlier, "rigid moving flux tube" models of Wei and Lee (1990) and Lockwood (1991) is that the latter do not consider the development of the open-closed field line boundary. The rigid tube models will necessarily distort this boundary up into ever-increasingly complicated folds. The evolving patch models, on the other hand, allow this boundary to maintain a simple (broadly $L$-shell aligned) form. In these models, the return flows expand with time, such that the open-closed boundary migrates equatorward at all local times. This expansion was directly observed by Lockwood et al. (1993b). The need for this expansion is clearly apparent when we compare the data in Fig. 5 with the simulations in Fig. 7.

\section{Summary and conclusions}

We have presented a study of simultaneous and colocated data sets from radar and optical instruments. In general, there is good spatial and temporal agreement between PMAFs and localised velocity enhancements in the radar data. It is also shown that the open/closed field line boundary, as determined by the spectral width of the line-of-sight radar velocity, corresponds well to the $3 \mathrm{kR}$ equatorward boundary of the $630 \mathrm{~nm}$ emission.

The analysis of the ASC and radar 1-o-s velocity data shows that the velocity of the PMAFs is similar to the convection velocity of the flow enhancements detected by the radar. This observation supports the ionospheric flow model put forward by Southwood (1987). The existence of equatorward flow patches in radar data indicated also a return flow outside a reconnected flux tube, as modelled by Southwood (1987). These observational facts lead to the simulation of this flow model in radar data, using the results of Wei and Lee (1990).

The simulated flow shows the general characteristics of the real data: a flow channel associated with the PMAF and return flow at the east- and westward edges of the event. Some of the differences between real and simulated data can be explained by the complexity of real data compared to the model: the temporal deformation of the PMAFs, and more than one structure contributing to the flow. The global modification of FACs in the cusp region could explain the weak return flow at the westward edge of events and the stronger 
than expected return flow at the eastward edge. The FAC modifications, due to the evolution of the shape of the patch of newly opened flux and also associated with the expansion of the flow towards dawn and dusk, such that the open-closed boundary maintains a simple, relatively undistorted form, are an important factor for understanding the small scale flow. Finally we presented schematics, based on observations, showing how the presence of multiple structures modifies poleward and equatorward flows.

Acknowledgements. A. Thorolfsson is funded by the European Commission under the Marie Curie Research Training Grant scheme (TMR grant ERBFMBICT971917). The operation of the Finland SuperDARN radar is supported by the Particle Physics and Astronomy Research Council, UK (PPARC grant PPA/R/R/ 1997/00256), the Swedish Institute for Space Physics, Uppsala, and the Finnish Meteorological Institute, Helsinki. The auroral observation program in Svalbard is supported by the Norwegian Research Council (Norges forskningsråd) and the Norwegian Polar Research Institute. The French SuperDARN activity is supported by the CNRS/INSU. The authors are grateful to R. Lepping and K. Oglivie at NASA/GSFC for the use of Wind MFI and SWE data, respectively.

Topical Editor M. Lester thanks M.J. Kosch and R. Fujii for their help in evaluating this paper.

\section{References}

Baker, K. B., and S. Wing, A new magnetic coordinate system for conjugate studies at high latitudes, J. Geophys. Res., 94, 91399143, 1989.

Baker, K. B., A. S. Rodger, and G. Lu, HF-radar observations of the rate of magnetic merging: A GEM boundary layer campaign study, J. Geophys. Res., 102, 9603-9617, 1997.

Chaston, C. C., H. J. Hansen, F. W. Menk, B. J. Fraser, and Y. D. $\mathrm{Hu}$, Ground signatures of convecting reconnected flux tubes, J. Geophys. Res., 98, 19 151-19 161, 1993.

Cowley, S. W. H., Excitation of flow in the Earth's magnetosphereionosphere system: observations by incoherent-scatter radar, in Polar cap boundary phenomena, Eds. J. Moen, A. Egeland, and M. Lockwood, vol 509 of NATO ASI series, 127-140, Kluwer, Dordrecht, The Netherlands, 1998.

Cowley, S.W.H., and M. Lockwood, Excitation and decay of solar wind-driven flow in the magnetosphere-ionosphere system, Ann. Geophysicae, 10, 103-115, 1992.

Cowley, S. W. H., M. P. Freeman, M. Lockwood, and M. F. Smith, The ionospheric signature of flux transfer events, in CLUSTER - dayside polar cusp, Ed. C. I. Barron, ESA SP-330, 105-112, European Space Agency Publications, Nordvijk, The Netherlands, 1991.

Denig, W. F., W. J. Burke, N. C. Maynard, F. J. Rich, B. Jacobsen, P. E. Sandholt, A. Egeland, S. Leontjev, and V. G. Vorobjev, Ionospheric signatures of dayside magnetopause transients: A case study using satellite and ground measurements, J. Geophys. Res., 98, 5969-5980, 1993.

Farrugia, C. J., M. P. Freeman, S. W. H. Cowley, D. J. Southwood, and M. Lockwood, Pressure-driven magnetopause motions and attendant response on the ground, Planet. Space Sci., 37, 589-607, 1989.

Fasel, G. J., J. I. Minow, R. W. Smith, C. S. Deehr, and L. C. Lee, Multiple brightenings of transient dayside auroral forms during oval expansions, Geophys. Res. Lett., 19, 2429-2432, 1992.

Fasel, G. J., L. C. Lee, and R. W. Smith, A mechanism for the multiple brightenings of dayside poleward-moving auroral forms, Geophys. Res. Lett., 20, 2247-2250, 1993.

Fasel, G. J., J. I. Minow, R. W. Smith, C. S. Deehr, and L. C. Lee, Multiple brightenings of poleward-moving dayside aural forms, in solar wind sources of magnetospheric ultra-low frequency waves, Eds. by M. J. Engebretson, K. Takahashi, and M. Scholer, vol 81 of Geophysical Monograph, pp 201-211, American Geophysical Union, Washington DC, USA, 1994.

Fox, N. J., M. Lockwood, S. W. H. Cowley, M. P. Freeman, E. Friis- Christensen, D. K. M. Pinnock, and G. D. Reeves, EISCAT observations of unusual flows in the norming sector associated with weak substorm activity, Ann. Geophysicae, 12, 541-553, 1994.

Greenwald, R. A., et al., DARN/SuperDARN: a global view of the dynamics of high-latitude convection, Space Sci. Rev., 71, 761-796, 1995.

Heelis, R. A., The effects of interplanetary magnetic field orientation on dayside high-latitude ionospheric convection, J. Geophys. Res., 89, 2873-2880, 1984.

Lee, L. C., Z. W. Ma, Z. F. Fu, and A. Otto, Topology of magnetic flux ropes and formation of fossil flux transfer events and boundary layer plasmas, J. Geophys. Res., 98, 3943-3951, 1993.

Lockwood, M., The excitation of ionospheric convection, J. Atmos. Terr. Phys., 53, 177-199, 1991.

Lockwood, M., Ionospheric signatures of pulsed magnetopause reconnection, in Physical signatures of magnetopause boundary layer processes, Eds. J. A. Holtet and A. Egeland, vol 425 of NATO ASI series, 229-243, Kluwer, Dordrecht, The Netherlands, 1994.

Lockwood, M., and M. F. Smith, The variation of reconnection rate at the dayside magnetopause and cusp ion precipitation, J. Geophys. Res., 97, 14,841-14,847, 1992.

Lockwood, M., P. E. Sandholt, S. W. H. Cowley, and T. Oguti, Interplanetary magnetic field control of dayside auroral activity and the transfer of momentum across the dayside magnetopause, Planet. Space Sci., 37, 1347-1365, 1989.

Lockwood, M., S. W. H. Cowley, P. E. Sandholt, and R. P. Lepping, The ionospheric signatures of flux transfer events and solar wind dynamic pressure changes, J. Geophys. Res., 95, 17 113$17135,1990$.

Lockwood, M., J. Carlson, H. C. and P. E. Sandholt, Implications of the altitude of transient 630-nm dayside auroral emissions, J. Geophys. Res., 98, 15 571-15 587, 1993 a.

Lockwood, M., J. Moen, S. W. H. Cowley, A. D. Farmer, U. P. Lovhaug, H. Luehr, and V. N. Davda, Variability of dayside convection and motions of the cusp/cleft aurora, Geophys, Res. Lett., 20, 1011-1014, 1993 b.

Lockwood, M., I. W. McCrea, S. E. Milan, J. Moen, J.-C. Cerisier, and A. Thorolfsson, Plasma structure within poleward-moving cusp/cleft auroral transients: EISCAT Svalbard observations and an explanation in terms of large local time extent of events, Ann. Geophysicae, 1999, submitted.

Lysak, R. L., Y. Song, and J. C. Grieger, Coupling of the magnetopause to the ionosphere by mease of Alfvén waves and field-aligned currents, in Physics of the magnetopause, Eds. P. Song, B. U. Ö. Sonnerup, and M. F. Thomsen, vol 90 of Geophysical Monograph, pp 385-393, American Geophysical Union, 1995.

McCrea, I. W., M. Lockwood, J. Moen, F. Pitout, P. Eglitis, and A. D. Aylward, ESR and EISCAT observations of the response of the cusp and cleft to IMF orientation changes, Ann. Geophysicae, 1999, submitted.

McHenry, M. A., and C. R. Clauer, Modeled ground magnetic signatures of flux transfer events, J. Geophys. Res., 92, 11 23111 240, 1987.

Milan, S. E., M. Lester, S. W. H. Cowley, J. Moen, P. E. sandholt, and C. J. Owen, Meridian-scanning photometer, coherent HF radar, and magnetometer observations of the cusp: a case study, Ann. Geophysicae, 17, 159-172, 1999.

Moen, J., D. P. E. Sandholt, M. Lockwood, W. F. Denig, U. P. Lovhaug, B. Lybekk, A. Egeland, D. Opsvik, and E. FriisChristensen, Events of enhanced convection and related dayside auroral activity, J. Geophys. Res., 100, 23 917-23 934, 1995.

Pinnock, M., A. S. Rodger, J. R. Dudeney, K. B. Baker, P. T. Newell, R. A. Greenwald, and M. E. Greenspan, Observations of 
an enhanced convection channel in the cusp ionosphere, J. Geophys. Res., 98, 3767-3776, 1993.

Pinnock, M., A. S. Rodger, J. R. Dudeney, F. Rich, and K. B. Baker, High spatial and temporal resolution observations of the ionospheric cusp, Ann. Geophysicae, 13, 919-925, 1995.

Pinnock, M., A. S. Rodger, K. B. Baker, G. Lu, and M. Hairston, Conjugate observations of the day-side reconnection electric field: A GEM boundary layer campaign, Ann. Geophysicae, 17, 443-454, 1999.

Provan, G., T. K. Yeoman, and S. E. Milan, High spatial and temporal resolution observations of the ionospheric cusps, Ann. Geophysicae, 16, 919-925, 1998.

Rodger, A. S., and M. Pinnock, The ionospheric response to flux transfer events: the first few minutes, Ann. Geophysicae, 15, 685691, 1997.

Sandholt, P. E., M. Lockwood, K. S. C. Freeman, T. Oguti, and S. W. H. Cowley, Midday auroral breakup events and related energy and momentum transfer from the magnetosheath, J. Geophys. Res., 95, 1039-1060, 1990.
Sandholt, P. E., C. J. Farrugia, J. Moen, Ø. Noraberg, B. Lybekk, T. Sten, and T. Hansen, A classification of dayside auroral forms and activities as a function of interplanetary magnetic field orientation, J. Geophys. Res., 103, 23 325-23 345, 1998 a.

Sandholt, P. E., C. J. Farrugia, M. Øieroset, P. Stauning, and W. F. Denig, Auroral activity associated with unsteady magnetospheric erosion: observations on December 18, 1990, J. Geophys. Res., 103, 2309-2317, 1998 b.

Sandholt, P. E., C. J. Farrugia, and B. Lybekk, The dynamic cusp aurora on 30 November 1997: response to southward turning of the IMF, Ann. Geophysicae, 17, 1155-1165, 1999.

Sibeck, D. G., Signatures of flux erosion from the dayside magnetosphere, J. Geophys. Res., 99, 8513-8529, 1994.

Siscoe, G. L., and T. S. Huang, Polar cap inflation and deflation, J. Geophys. Res., 90, 543-547, 1985.

Southwood, D. J., The ionospheric signature of flux transfer events, J. Geophys. Res., 92, 3207-3213, 1987.

Wei, C. Q., and L. C. Lee, Ground magnetic signatures of moving elongated plasma clouds, J. Geophys. Res., 95, 2405-2418, 1990. 